\title{
Editorial
}

\section{Anticytotics - Radiopalliation/chemopalliation and neuraxial neoplasms}

\author{
Manu Kothari, Atul Goel ${ }^{1}$ \\ Departments of Anatomy and ${ }^{1}$ Neurosurgery, King Edward Memorial Hospital and Seth G.S. Medical College, Parel, Mumbai, India
}

The Bard of Stratford-on-Avon, has aphorized in Romeo and Juliet $(2, \mathrm{ii}, 43)$ that "a rose, by any other name, would smell as sweet". Given his versatility, he would have loved to complete the story by adding that "a thorn, by any other name, would prick as deep". To euphemistically elevate radiation/chemicals to the status of therapy ("art of healing") is to present thorny palliation as rosy treatment. Such verbal trickery deludes the oncologists and devastates the unsuspecting patient. In the increasingly eyeless monetaristic medical scene, the age-old caution of caveat emptor - Let the buyer beware, has to hold a red light to the buyer, namely, the cancer patient, through some semantic honesty.

Chemomimetic radiation and radiomimetic chemicals are agents that indiscriminately age or ravage an animal cell, so as to earn the appellation anticytotic. Nobelist Solzhenitsyn, the Tolstoy of our times, in his highly illuminating novel Cancer Ward, poses this reality through the hero, Oleg, to whom the medicallyadvertised "differential" effects of irradiation were not at all clear. He wondered how "the harsh X-rays, the trembling vectors of electric and magnetic fields could bomb a tumor without touching the rest of the body". Oleg searched for an answer from his oncologist Vera Kornilyevna, but "What could she tell him about the blind artillery which cuts down its own men with the same pleasure as it does the enemy's?" What is true for so-called radiotherapy is true for the so-called chemotherapy as well. The oncologically convenient assumption that oncocytokinetics are more rapid than normocytokinetics has been nailed long ago. Going by the ceaseless rapidity with which epidermis, mucosae, and bone marrow cells multiply, the trade-off is that before a cancer cell may be killed, a million normal cells, will be. From the simplistic Roentgenian beam through the latest accelerator, the foregoing truth has remained unchanged.

\section{Historical background}

Within months after its discovery by Roentgen, in 1894, the X-ray was introduced widely into the iagnosis and treatment of disease. At the same time, harmful effects of radiation were encountered almost immediately. The first such effects to be recognized typically appeared within hours or days after exposure and rapidly subsided.

It was not until 1902 that cancer, arising on the hand of a radiologist at the site of radiation induced skin damage, was recognized as a potential late-occurring complication of radiation injury. In the ensuing decades, before safety measures were improved, similar growths occurred in scores of pioneer radiation workers.

The implication that any dose of radiation, however small, might involve some risks of serious injury aroused concerns which have persisted to the present. As a result, radiation protection standards no longer assume the existence of a level of exposure that is totally 'safe'. (The Oxford Companion to Medicine, 1986)

The above radiational history makes it clear that radiation has been, a priori foreknowingly, cancerogenic. The late Karnofsky, chief of cancer chemotherapy as SKI, NY, launches his chapter thereon with a very revealing generalization: "If an agent has certain biologic effects, such as carcinogenic, mutagenic, or bone-marrow-depressant activity, it merits testing for chemotherapeutic activity against cancer". So, it has been, so far. Cancer chemotherapy owes its beginning to sulfur mustards (World War One) and, the latterly developed nitrogen mustards (World War Two). "The disappearance of lymphocytes and granulocytes from the blood of rabbits was a useful marker of toxicity and gave rise to the idea of possible efficacy in lymphoid cancer". From 1945, till to-date, the cytocidal ambivalence of the so-called cancer chemotherapy remains the writing on the wall. The latest, $7^{\text {th }}$ edition of Oxford Handbook of Clinical Medicine, 2007, pulls no punches:

\section{Immunosuppressive drugs}

As well as being used in leukemias and cancer, these 
are used in organ and marrow transplants, rheumatoid arthritis, psoriasis, chronic hepatitis, asthama, SLE, vasculitis (eg Wegener's giant cell arteritis, polymyalgia, PAN), inflammatory bowel and other diseases (so this page could figure in almost any chapter).

This parenthesis, by the Handbook itself, is proofpositive of the indiscriminate cytotoxic nature of the so-called anticancer drugs.

What do anticytotics - radiational or chemical - do to cells? As of today, medical science knows naught. The entire biosphere owes its existence to solar radiation that, quickening chlorophyll, creates the fabulous food chain. Your mobiles work only because of radiation. The so-called therapeutic radiation is a high-energy electromagnetic beam that, to say the least, ionizes a cell to ravage it or age it. Actively dividing cells die. Non-dividing cells age. The result is short-term or long-term inflammation, vasculitis, and overall aging. Ionizing radiation does NOT cause cancer per se, but by aging a cells drags it closer to its inbuilt cancerous destination.

Chemical anticytotics mimic ionizing radiation and their side effects (which is reality are main-effects) strongly resembles those of radiation. Body's survival instinct tends to deload circulatory blood of these toxins by exiling them to avascular areas such as epithelia, mucosae, and bone-marrow; wherein the maximal impact of toxicity occurs. The above tissues being renewing in nature have the highest mitotic rate (exceeding the fastest growing cancer), and hence have a very high population of dividing cells that take all the insult from radiation and chemicals. Epidermitis produces sour mouth, sore passages and sore exits, hence cystitis, urethritis, and proctitis. Bone marrow depression has all the predictable effects. The constellation of side-effects makes an average cancer patient forget his/her cancer.

From the above basics, let us move on to hardcore oncologic practice to glean some truth from the 4-megatome, 5296 pages, 20 editors, 629 authors, 108 page 3 -column index titled Youmans Neurological Surgery, $5^{\text {th }}$ edition, 2004, "Chemotherapy can benefit some patients with CNS tumors to a modest extent, but the most effective drugs or drug regimens and the best method of delivery are unknown". Radiotherapy looks as nebulous: "Although much is known about the radiobiology of radiotherapy in the central nervous system, there is even more that is unknown. Hence, we have merely scratched the surface in discovering how radiation works and its potential use in treating disease." The complications of radiotherapy are acute/subacute/ late. Acute ones are more because of skin damage and are evanescent. Subacute, several weeks/months after therapy are complex, comprise somnolence, syndromes of demyelination, dysphasia, cerebellar ataxia and ocular damage.
Late complications, occurring after several months or years, comprise radiation necrosis, mineralized angiopathy, enlarged ventricles, microcalcifications, dementia, ataxia, significant white matter atrophy, neurocognitive impairment; optic neuropathy, hypopituitarism, stroke, and development of secondary neoplasm. Regardless of the above, "The most common malignant tumor of the brain is a secondary metastatic deposit, which is most often treated with radiation therapy".

If, 114 years post-Roentgen, and 64 years postmustards, there does not seem to be enough light at the end of the anticytotic tunnel, then, may be we are in need of a revised weltanschauung on the thorny issue. Should you grudge that this is all philosophy but no science, please note that lexicons define philosophy as scientia scientarium- meaning, science of all sciences. Set below are a few points-

1 Voltaire averred that humanity's chief penchant is to foist unreason through the use of reason. Cancer has NO treatment. What is treated is signs and/ or symptoms which is but palliation (from pall = coffin). All palliation rests on coffining the clarity on the primary disease, and merely easing whatever the disease. And if radiopalliation and chemopalliation are predictably pathogenic, can they ever be christened as palliatives.

2 "The science of therapeutics", Bodley Scott observed "is founded on the touchingly naïve assumption that there is an answer to every question it poses". We always ask "What is the treatment of this disease?", but not "Is there a treatment of this disease?" The universal illusion is that treatment and effectiveness go together.

3 Glemser, in his globe-trotting survey Man Against Cancer concluded that surgery is best avoided, radiotherapy is obsolete, chemotherapy is "an avoidable farce".

4 Yet the common oncological textbook generalization that the three primary modes of cancer therapy are surgery, radiation and chemical spring from what Richard Asher, the British medical wit, generalizes: It's better to believe in therapeutic nonsense than to admit therapeutic bankruptcy.

5 Osler observed that mankind ails from must-treatism. Yet a survey of American doctors who themselves had cancer showed that most of them had no faith in any of the above modes of treatment nor in the so-called early diagnosis.

The BMJ asked the Director of Surgery at St. Mary's Hospital, London, what he would do if he had cancer of rectum. His submission is a revelation by itself: 'I am absolutely certain - and this I am sure will bring wrath of most colorectal surgeons on my head, but no matter - I would not have an dominoperineal resection with a colostomy. However managed, however much we delude ourselves, a permanent 
potentially incontinent abdominal anus is an affront difficult to bear, so I marvel that we and our patients have put up with it so long. It says much for the social indifference of the one and the social fortitude of the other'. (Dudley, H.A.F.: If I had carcinoma of the middle third of the rectum. Brit. Med. J., $1: 1035,1978$

6 The intellectual bankruptcy of oncology and hazards of anticytotics get revealed by Current Medical Diagnosis and Treatment 2008, a celebrated yearly tome, in so many languages: "The single most important risk factor for developing cancer is age. AboutAbout 76\% of cancers are diagnosed in persons aged 75 years or older..... An additional cause of cancer is chemotherapy or radiotherapy for prior malignancy".
"In my experience, for what it may be worth, it does not usually work out in the long-run to be seduced into telling the untruth". This plea by an oncologist is supplemented by a declaration from a cancer-patient:'The time to be honest about cancer is now." The time to be honest about tumor radiotherapy or chemotherapy, neuraxis or elsewhere, is now. Both do not deserve the euphemism palliation. How about describing each of these as a MOTTO- Medicine/Measure Of Troublesome Trade-Off?That done, you, as a neuron-onco-therapist have empowered your patient by a general rule of the thumb in making a choice. Buyer (of treatment or MOTTO), beware.

And this caution urges that the patient rather put up with the cancer, or ask for anticytotics, understanding fully well the price that the body must pay from scalp-hair to toe-nails. So if a person is at ease with the primary/secondary tumor, no anticytotic is needed. If the dis-ease is compelling, the purely palliative nature and the price -to-be-paid must be written in neon letters. 